\title{
Passerine swarm optimization algorithm for solving optimal reactive power dispatch problem
}

\author{
Lenin Kanagasabai \\ Department of EEE, Prasad V. Potluri Siddhartha Institute of Technology, India
}

\begin{tabular}{l} 
Article Info \\
\hline Article history: \\
Received Jan 3, 2020 \\
Revised Feb 11, 2020 \\
Accepted Mar 14, 2020
\end{tabular}

Keywords:

Optimal

Passerine bird

Reactive power

Swarm-intelligence

Transmission loss

\begin{abstract}
This paper presents Passerine Swarm Optimization Algorithm (PSOA) for solving optimal reactive power dispatch problem. This algorithm is based on behaviour of social communications of Passerine bird. Basically, Passerine bird has three common behaviours: search behaviour, adherence behaviour and expedition behaviour. Through the shared communications Passerine bird will search for the food and also run away from hunters. By using the Passerine bird communications and behaviour, five basic rules have been created in the PSOA approach to solve the optimal reactive power dispatch problem. Key aspect is to reduce the real power loss and also to keep the variables within the limits. Proposed Passerine Swarm Optimization Algorithm (PSOA) has been tested in standard IEEE 30 bus test system and simulations results reveal about the better performance of the proposed algorithm in reducing the real power loss and enhancing the static voltage stability margin.
\end{abstract}

This is an open access article under the CC BY-SA license.

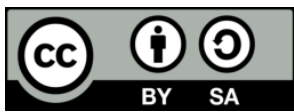

\section{Corresponding Author:}

Lenin Kanagasabai

Department of EEE,

Prasad V. Potluri Siddhartha Institute of Technology,

Kanuru, Vijayawada, Andhra Pradesh-520007, India.

Email: gklenin@gmail.com

\section{INTRODUCTION}

Optimal reactive power dispatch problem is subject to number of uncertainties and at least in the best case to uncertainty parameters given in the demand and about the availability equivalent amount of shunt reactive power compensators. Optimal reactive power dispatch plays a major role for the operation of power systems, and it should be carried out in a proper manner, such that system reliability is not got affected. The main objective of the optimal reactive power dispatch is to maintain the level of voltage and reactive power flow within the specified limits under various operating conditions and network configurations. By utilizing a number of control tools such as switching of shunt reactive power sources, changing generator voltages or by adjusting transformer tap-settings the reactive power dispatch can be done. By doing optimal adjustment of these controls in different levels, the redistribution of the reactive power would minimize transmission losses. This procedure forms an optimal reactive power dispatch problem and it has a major influence on secure and economic operation of power systems. Various mathematical techniques like the gradient method Alsac et al . Lee et al and linear programming mangoli et al [1-7] have been adopted to solve the optimal reactive power dispatch problem. Both the gradient and Newton methods has the difficulty in handling inequality constraints. If linear programming is applied then the input- output function has to be expressed as a set of linear functions which mostly lead to loss of accuracy. This paper formulates by combining both the real power loss minimization and maximization of static voltage stability margin (SVSM) as the objectives. Global optimization has received extensive research attention, and a great number 
of methods have been applied to solve this problem. Many Evolutionary algorithms Aparajita Mukherjee et al., $\mathrm{Hu}$ et al., Mahaletchumi et al., Sulaiman et al., Pandiarajan et al.,have been already proposed to solve the reactive power flow problem. This paper presents Passerine Swarm Optimization Algorithm (PSOA) for solving optimal reactive power dispatch problem. This algorithm is based on behaviour of social communications of Passerine bird Anderson et al., Barnard et al., Beauchamp et al., Bednekoff et al., Coolen et al. [8-13]. Basically Passerine bird has three common behaviours: search behaviour, adherence behaviour and expedition behaviour. Through the shared communications Passerine bird will search for the food and also run away from hunters [14-20]. By using the Passerine bird communications and behaviour, five basic rules have been created in the PSOA approach to solve the optimal reactive power dispatch problem. Key aspect is to reduce the real power loss and also to keep the variables within the limits. Proposed Passerine Swarm Optimization Algorithm (PSOA) has been tested in standard IEEE 30 bus test system and simulations results reveal about the better performance of the proposed algorithm in reducing the real power loss and enhancing the static voltage stability margin.

\section{VOLTAGE STABILITY EVALUATION}

odal analysis for voltage stability evaluation; Modal analysis is one among best methods for voltage stability enhancement in power systems. The steady state system power flow are given by (1).

$$
\left[\begin{array}{l}
\Delta \mathrm{P} \\
\Delta \mathrm{Q}
\end{array}\right]=\left[\begin{array}{cc}
\mathrm{J}_{\mathrm{p} \theta} \mathrm{J}_{\mathrm{pv}} \\
\mathrm{J}_{\mathrm{q} \theta} & \mathrm{J}_{\mathrm{QV}}
\end{array}\right]\left[\begin{array}{l}
\Delta \theta \\
\Delta V
\end{array}\right]
$$

Where

$\Delta \mathrm{P}=$ Incremental change in bus real power.

$\Delta \mathrm{Q}=$ Incremental change in bus reactive Power injection

$\Delta \theta=$ incremental change in bus voltage angle.

$\Delta \mathrm{V}=$ Incremental change in bus voltage Magnitude

Jp $\theta$, JPV , JQ $\theta$, JQV jacobian matrix are the sub-matrixes of the System voltage stability is affected by both $\mathrm{P}$ and $\mathrm{Q}$.

To reduce (1), let $\Delta \mathrm{P}=0$, then.

$$
\begin{aligned}
& \Delta \mathrm{Q}=\left[\mathrm{J}_{\mathrm{QV}}-\mathrm{J}_{\mathrm{Q} \theta} \mathrm{J}_{\mathrm{P} \theta^{-1} \mathrm{~J}_{\mathrm{PV}}}\right] \Delta \mathrm{V}=\mathrm{J}_{\mathrm{R}} \Delta \mathrm{V} \\
& \Delta \mathrm{V}=\mathrm{J}^{-1}-\Delta \mathrm{Q}
\end{aligned}
$$

Where

$$
\mathrm{J}_{\mathrm{R}}=\left(\mathrm{J}_{\mathrm{QV}}-\mathrm{J}_{\mathrm{Q} \theta} \mathrm{J}_{\mathrm{P \theta}}{ }^{-1} \mathrm{JPV}\right)
$$

$\mathrm{J}_{\mathrm{R}}$ is called the reduced Jacobian matrix of the system.

Modes of Voltage instability:

Voltage Stability characteristics of the system have been identified by computing the Eigen values and Eigen vectors.

Let

$$
\mathrm{J}_{\mathrm{R}}=\xi \wedge \eta
$$

Where,

$\xi=$ right eigenvector matrix of JR

$\eta=$ left eigenvector matrix of JR

$\Lambda=$ diagonal eigenvalue matrix of JR and

$$
\mathrm{J}_{\mathrm{R}^{-1}}=\xi \wedge^{-1} \eta
$$

From (5) and (8), we have

Or

$$
\Delta \mathrm{V}=\xi \wedge^{-1} \eta \Delta \mathrm{Q}
$$




$$
\Delta \mathrm{V}=\sum_{\mathrm{I}} \frac{\xi_{\mathrm{i}} \eta_{\mathrm{i}}}{\lambda_{\mathrm{i}}} \Delta \mathrm{Q}
$$

Where $\xi \mathrm{i}$ is the ith column right eigenvector and $\eta$ the ith row left eigenvector of JR. $\lambda i$ is the ith Eigen value of JR. The ith modal reactive power variation is,

$$
\Delta Q_{\mathrm{mi}}=\mathrm{K}_{\mathrm{i}} \xi_{\mathrm{i}}
$$

where,

$$
\mathrm{K}_{\mathrm{i}}=\sum_{\mathrm{j}} \xi_{\mathrm{ij}}-1
$$

Where

$\xi j i$ is the jth element of $\xi \mathrm{i}$

The corresponding ith modal voltage variation is

$$
\Delta \mathrm{V}_{\mathrm{mi}}=\left[1 / \lambda_{\mathrm{i}}\right] \Delta \mathrm{Q}_{\mathrm{mi}}
$$

If $|\lambda \mathrm{i}|=0$ then the $i$ th modal voltage will collapse .

In (10), let $\Delta \mathrm{Q}=\mathrm{ek}$ where ek has all its elements zero except the kth one being 1 . Then,

$$
\Delta \mathrm{V}=\sum_{\mathrm{i}} \frac{\mathrm{\eta}_{1 \mathrm{k}} \xi_{1}}{\lambda_{1}}
$$

$\eta_{1 \mathrm{k}} \mathrm{k}$ th element of $\eta_{1}$

$\mathrm{V}-\mathrm{Q}$ sensitivity at bus $\mathrm{k}$

$$
\frac{\partial \mathrm{V}_{\mathrm{K}}}{\partial \mathrm{Q}_{\mathrm{K}}}=\sum_{\mathrm{i}} \frac{\mathrm{\eta}_{1 \mathrm{k}} \xi_{1}}{\lambda_{1}}=\sum_{\mathrm{i}} \frac{\mathrm{P}_{\mathrm{ki}}}{\lambda_{1}}
$$

\section{PROBLEM FORMULATION}

The objectives of the reactive power dispatch problem is to minimize the system real power loss and maximize the static voltage stability margins (SVSM).

\subsection{Minimization of real power loss}

Minimization of the real power loss (Ploss) in transmission lines is mathematically stated as (14).

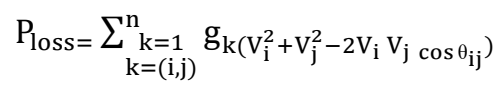

Where $\mathrm{n}$ is the number of transmission lines, gk is the conductance of branch $\mathrm{k}, \mathrm{Vi}$ and $\mathrm{Vj}$ are voltage magnitude at bus $i$ and bus $j$, and $\theta \mathrm{ij}$ is the voltage angle difference between bus $i$ and bus $j$.

Minimization of Voltage Deviation. Minimization of the voltage deviation magnitudes (VD) at load buses is mathematically stated as (15).

$$
\text { Minimize } \mathrm{VD}=\sum_{\mathrm{k}=1}^{\mathrm{nl}}\left|\mathrm{V}_{\mathrm{k}}-1.0\right|
$$

Where $\mathrm{nl}$ is the number of load busses and $\mathrm{Vk}$ is the voltage magnitude at bus $\mathrm{k}$.

\subsection{System constraints}

The following is an objective function that experiences constraints.

a. Load flow equality constraints:

$$
\begin{aligned}
& P_{G i}-P_{D i}-V_{i} \sum_{j=1}^{n b} V_{j}\left[\begin{array}{cc}
G_{i j} & \cos \theta_{i j} \\
+B_{i j} & \sin \theta_{i j}
\end{array}\right]=0, i=1,2 \ldots, n b \\
& Q_{G i}-Q_{D i}-V_{i} \sum_{j=1}^{n b} V_{j}\left[\begin{array}{cc}
G_{i j} & \sin \theta_{i j} \\
+B_{i j} & \cos \theta_{i j}
\end{array}\right]=0, i=1,2 \ldots ., n b
\end{aligned}
$$


where, $\mathrm{nb}$ is the number of buses, $\mathrm{PG}$ and QG are the real and reactive power of the generator, PD and QD are the real and reactive load of the generator, and Gij and Bij are the mutual conductance and susceptance between bus $\mathrm{i}$ and bus $\mathrm{j}$.

b. Generator bus voltage (VGi) inequality constraint:

$$
\mathrm{V}_{\mathrm{Gi}}^{\min } \leq \mathrm{V}_{\mathrm{Gi}} \leq \mathrm{V}_{\mathrm{Gi}}^{\max }, \mathrm{i} \in \mathrm{ng}
$$

c. Load bus voltage (VLi) inequality constraint:

$$
\mathrm{V}_{\mathrm{Li}}^{\min } \leq \mathrm{V}_{\mathrm{Li}} \leq \mathrm{V}_{\mathrm{Li}}^{\max }, \mathrm{i} \in \mathrm{nl}
$$

d. Switchable reactive power compensations (QCi) inequality constraint:

$$
\mathrm{Q}_{\mathrm{Ci}}^{\min } \leq \mathrm{Q}_{\mathrm{Ci}} \leq \mathrm{Q}_{\mathrm{Ci}}^{\max }, \mathrm{i} \in \mathrm{nc}
$$

e. Reactive power generation (QGi) inequality constraint:

$$
\mathrm{Q}_{\mathrm{Gi}}^{\min } \leq \mathrm{Q}_{\mathrm{Gi}} \leq \mathrm{Q}_{\mathrm{Gi}}^{\max }, \mathrm{i} \in \mathrm{ng}
$$

f. Transformers tap setting (Ti) inequality constraint:

$$
\mathrm{T}_{\mathrm{i}}^{\min } \leq \mathrm{T}_{\mathrm{i}} \leq \mathrm{T}_{\mathrm{i}}^{\max }, \mathrm{i} \in \mathrm{nt}
$$

g. Transmission line flow (SLi) inequality constraint:

$$
\mathrm{S}_{\mathrm{Li}}^{\min } \leq \mathrm{S}_{\mathrm{Li}}^{\max }, \mathrm{i} \in \mathrm{nl}
$$

Where, nc, ng and nt are numbers of the switchable reactive power sources, generators and transformers.

\section{PASSERINE BIRD SWARM HYPOTHESIS}

The Passerine bird Figure 1 social behavior's can be written as follows:

a) Rule 1. Every Passerine bird has choice to alter between the adherence behaviour and search behaviour. Whether the Passerine bird searches or in observance, it is molded as a stochastic decision.

b) Rule 2. While search, each Passerine bird can promptly record and renovate its previous most outstanding experience and the swarms' previous most outstanding experience about food area. This information has been used to discover food. Social information is shared rapidly among the whole swarm.

c) Rule 3. During adherence, every Passerine will attempt to move near to the centre of the swarm. This behaviour can be embroidered by the interference tempted by the rivalry among swarm. The Passerine with the uppermost reserves would be more prone to lie nearer to the centre of the swarm.

d) Rule 4. While flying Passerine may often change between generating and sponging. The Passerine with the uppermost reserves would be a creator, while the one with the bottom most reserves would be a sponger. Passerine have reserves between the uppermost and bottom most reserves would randomly choose to be creator and sponger.

e) Rule 5. Creators with desire search for food. Spongers would randomly follow a creator to search for food. By the above Rules the mathematical model for the problem has been developed,

All $N$ virtual Passerine bird, portrayed by their position $Z_{-} t^{\wedge} i(i \in[1 \ldots, N])$ at time step $t$, search for food and fly in an organized space. 


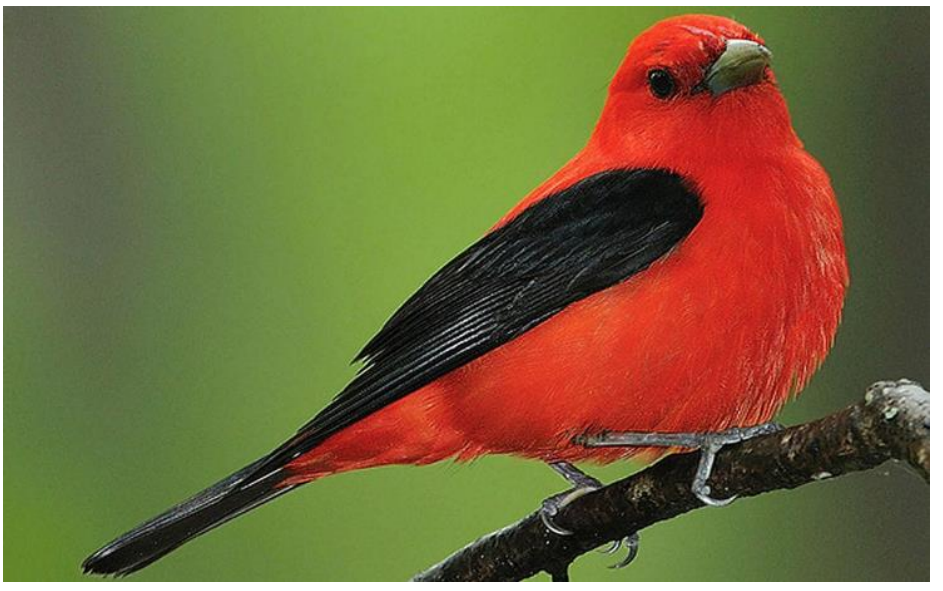

Figure 1. Passerine bird

\subsection{Search behaviour} as follows,

Every Passerine will search for food according to its experience. Rule 2 can be written in (24)

$$
Z_{i, j}^{t+1}=Z_{i, j}^{t}+\left(k_{i, j}-Z_{i, j}^{t}\right) \times M \times \operatorname{rand}(0,1)+\left(l_{j}-Z_{i, j}^{t}\right) \times N \times \operatorname{rand}(0,1)
$$

Where $j \in[1, \ldots, C]$, rand $(0,1)$ denotes independent uniformly distributed numbers in $(0,1)$.

$\mathrm{M}$ and $\mathrm{N}$ are two positive numbers, which can be respectively called as cognitive and social accelerated coefficients. $k_{i, j}$ is the best preceding position of the $i_{\text {th }}$ passerine and $l_{j}$ is the most excellent preceding position shared by the swarm.

The Rule 1 can be defined as a stochastic decision. If a uniform arbitrary number in $(0,1)$ is smaller than, $K(K \in(0,1))$ a constant value, the Passerine would search for food. Otherwise, the passerine would carry on observance.

\subsection{Adherence behaviour}

Rule 3 indicates that passerine would try to move nearthe Centre of the swarm, and they would inevitably contend with each other. Thus, each Passerine cannot directly move towards the Centre of the swarm. This drive can be written as follows:

$$
\begin{aligned}
& Z_{i, j}^{t+1}=Z+F 1\left(\text { mean }_{v}-Z_{i, j}^{t}\right) \times \operatorname{rand}(0,1)+F 2\left(K_{k, j}-Z_{i, j}^{t}\right) \times \operatorname{rand}(-1,1) \\
& F 1=f 1 \times \exp \left(-\frac{k f i t_{i}}{\text { sumFit }+\varepsilon} \times N\right) \\
& F 2=f 2 \times \exp \left(\left(\frac{\text { kFit }_{i}-k F i t_{r}}{\mid \text { kFit }_{r}-k F i t_{i} \mid+\varepsilon}\right) \frac{N \times k F i t_{r}}{\text { sumFit }+\varepsilon}\right)
\end{aligned}
$$

Where $k(k \neq 1)$ is a positive integer, which is illogically chosen between 1 and $\mathrm{N}$. $\mathrm{f} 1$ and $\mathrm{f} 2$ are two positive constants in [0,2], $k$ Fit $_{i}$ denotes the ith passerine best fitness value and sumFit represents the sum of

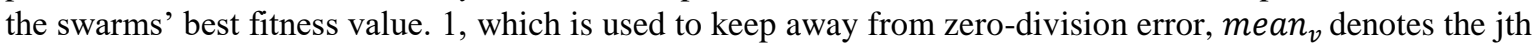
element of the average position of the whole swarm. When a Passerine move near the Centre of the swarm, it will unavoidably compete with each other. The average fitness value of the swarm is measured by the surrounding swarm when a Passerine move to the Centre of the swarm. Each Passerine always wants to position at the Centre of swarm, the product of F1 and rand $(0,1)$ should not be more than 1 . Here, F2 is used to create the direct effect persuaded by interference when a Passerine move to the Centre of the swarm. If the most outstanding fitness value of a random $k_{t h}$ Passerine $(k-i)$ is greater than that of the ith Passerine, then F2, f2 which means that the $i_{\text {th }}$ may bear Passerine a greater interference than the $k_{\text {th }}$ Passerine. The $\mathrm{k}_{\mathrm{th}}$ Passerine would be move near the centre of the swarm than the ith passerine. 


\subsection{Expedition behaviour}

Passerine may fly to other areas due to countless reasons. When the Passerine arrived at an innovative site, they would again search for food. Some Passerine as creators would search for food patches, while other Passerine try to feed from the food patch found by the creators. By the Rule 4 the creators and spongers can be detached from the swarm. The behaviors of the creators and spongers can be written as follows:

$$
\begin{aligned}
& Z_{i, j}^{t+1}=Z_{i, j}^{t}+\operatorname{randn}(0,1) \times Z_{i, j}^{t} \\
& Z_{i, j}^{t+1}=Z_{i, j}^{t}+\left(Z_{k, j}^{t}-Z_{i, j}^{t}\right) \times G H \times \operatorname{rand}(0,1)
\end{aligned}
$$

Where $\operatorname{randn}(0,1)$ denotes Gaussian distributed arbitrary number with mean zero and standard deviation $1, k \in[1,2,3, \ldots, N], k \neq i . G H(G H \in[0,2])$ means that the sponger would follow the creator to search for food. We assume that each Passerine fly to alternative place every $\mathrm{GH}$ (positive integer) unit interval.

\subsection{Passerine bird Swarm optimization Algorithm for optimal reactive power dispatch problem}

Enter: P: the number of individuals (passerine) bounded in the population, Q: the utmost number of iterations, $G H$ : the rate of repetition of Passerine expedition behaviors', K: the probability of searching for food, $\mathrm{M}, \mathrm{N}, \mathrm{f} 1, \mathrm{f} 2, \mathrm{GH}$ : are five constant parameters, $t=0$; Initialize the population

Assessment of the $\mathrm{N}$ individuals' fitness value, and find the most outstanding solution

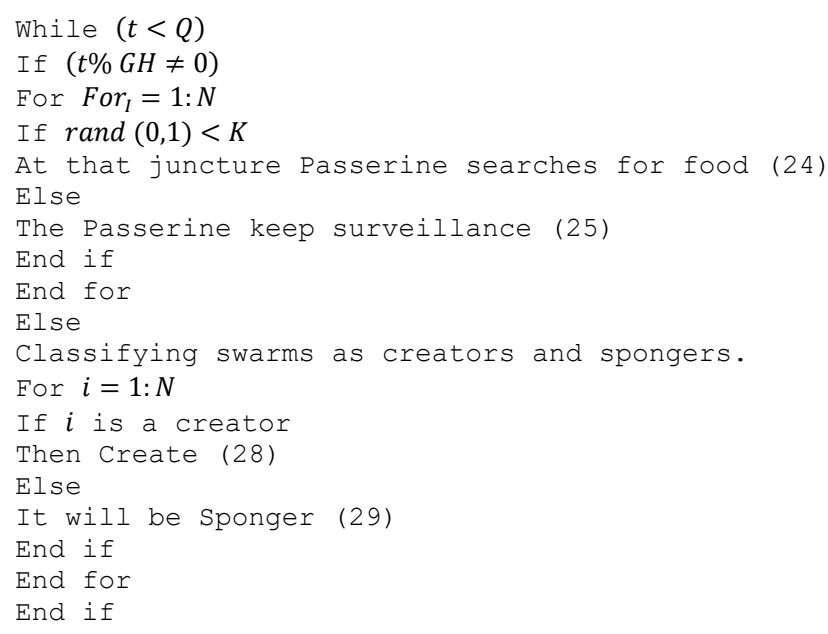

Calculate innovative solutions. If the innovative solutions are greater to their previous ones, renovate them. Find the current most outstanding solution

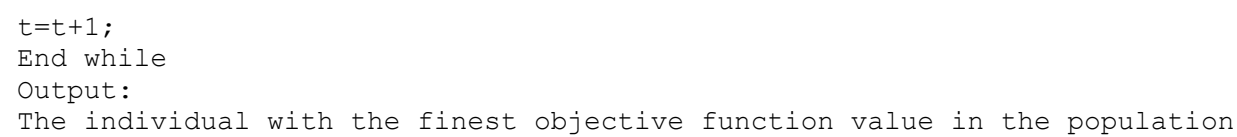

\section{SIMULATION RESULTS}

The efficiency of the proposed Passerine Swarm Optimization Algorithm (PSOA) method is demonstrated by testing it on standard IEEE-30 bus system. The IEEE-30 bus system has 6 generator buses, 24 load buses and 41 transmission lines of which four branches are (6-9), (6-10), (4-12) and (28-27) - are with the tap setting transformers. The lower voltage magnitude limits at all buses are 0.95 p.u. and the upper limits are 1.1 for all the PV buses and 1.05 p.u. for all the PQ buses and the reference bus. The simulation results have been presented in Tables 1, Table 2, Table $3 \&$ Table 4 . The Table 5 shows the proposed algorithm powerfully reduces the real power losses when compared to other given algorithms. The optimal values of the control variables along with the minimum loss obtained are given in Table 1. Corresponding to this control variable setting, it was found that there are no limit violations in any of the state variables.

Optimal Reactive Power Dispatch problem together with voltage stability constraint problem was handled in this case as a multi-objective optimization problem where both power loss and maximum voltage 
stability margin of the system were optimized simultaneously. Table 2 indicates the optimal values of these control variables. Also it is found that there are no limit violations of the state variables. It indicates the voltage stability index has increased from 0.2452 to 0.2466 , an advance in the system voltage stability. To determine the voltage security of the system, contingency analysis was conducted using the control variable setting obtained in case 1 and case 2 . The Eigen values equivalents to the four critical contingencies are given in Table 3. From this result it is observed that the Eigen value has been improved considerably for all contingencies in the second case.

Table 1.Results of PSOA - ORPD optimal control variables

\begin{tabular}{cc}
\hline Control variables & Variable setting \\
\hline V1 & 1.032 \\
V2 & 1.030 \\
V5 & 1.033 \\
V8 & 1.031 \\
V11 & 1.000 \\
V13 & 1.029 \\
T11 & 1.00 \\
T12 & 1.00 \\
T15 & 1.00 \\
T36 & 1.01 \\
Qc10 & 2 \\
Qc12 & 2 \\
Qc15 & 3 \\
Qc17 & 0 \\
Qc20 & 2 \\
Qc23 & 3 \\
Qc24 & 3 \\
Qc29 & 2 \\
Real power loss & 4.2502 \\
SVSM & 0.2452 \\
\hline
\end{tabular}

Table 2. Results of PSOA -voltage stability control reactive power dispatch optimal control variables

\begin{tabular}{cc}
\hline Control Variables & Variable Setting \\
\hline V1 & 1.040 \\
V2 & 1.039 \\
V5 & 1.040 \\
V8 & 1.029 \\
V11 & 1.000 \\
V13 & 1.030 \\
T11 & 0.090 \\
T12 & 0.090 \\
T15 & 0.090 \\
T36 & 0.090 \\
Qc10 & 3 \\
Qc12 & 3 \\
Qc15 & 2 \\
Qc17 & 3 \\
Qc20 & 0 \\
Qc23 & 2 \\
Qc24 & 2 \\
Qc29 & 3 \\
Real power loss & 4.9860 \\
SVSM & 0.2466 \\
\hline
\end{tabular}

Table 3. Voltage stability under contingency state

\begin{tabular}{cccc}
\hline Sl.No & Contingency & ORPD Setting & VSCRPD Setting \\
\hline 1 & $28-27$ & 0.1409 & 0.1424 \\
2 & $4-12$ & 0.1649 & 0.1652 \\
3 & $1-3$ & 0.1769 & 0.1779 \\
4 & $2-4$ & 0.2029 & 0.2041 \\
\hline
\end{tabular}


Table 4. Limit violation checking of state variables

\begin{tabular}{|c|c|c|c|c|}
\hline \multirow{2}{*}{ State variables } & \multicolumn{2}{|c|}{ limits } & \multirow{2}{*}{ ORPD } & \multirow{2}{*}{ VSCRPD } \\
\hline & Lower & upper & & \\
\hline Q1 & -20 & 152 & 1.3422 & -1.3269 \\
\hline Q2 & -20 & 61 & 8.9900 & 9.8232 \\
\hline Q5 & -15 & 49.92 & 25.920 & 26.001 \\
\hline Q8 & -10 & 63.52 & 38.8200 & 40.802 \\
\hline Q11 & -15 & 42 & 2.9300 & 5.002 \\
\hline Q13 & -15 & 48 & 8.1025 & 6.033 \\
\hline V3 & 0.95 & 1.05 & 1.0372 & 1.0392 \\
\hline V4 & 0.95 & 1.05 & 1.0307 & 1.0328 \\
\hline V6 & 0.95 & 1.05 & 1.0282 & 1.0298 \\
\hline V7 & 0.95 & 1.05 & 1.0101 & 1.0152 \\
\hline V9 & 0.95 & 1.05 & 1.0462 & 1.0412 \\
\hline V10 & 0.95 & 1.05 & 1.0482 & 1.0498 \\
\hline V12 & 0.95 & 1.05 & 1.0400 & 1.0466 \\
\hline V14 & 0.95 & 1.05 & 1.0474 & 1.0443 \\
\hline V15 & 0.95 & 1.05 & 1.0457 & 1.0413 \\
\hline V16 & 0.95 & 1.05 & 1.0426 & 1.0405 \\
\hline V17 & 0.95 & 1.05 & 1.0382 & 1.0396 \\
\hline V18 & 0.95 & 1.05 & 1.0392 & 1.0400 \\
\hline V19 & 0.95 & 1.05 & 1.0381 & 1.0394 \\
\hline V20 & 0.95 & 1.05 & 1.0112 & 1.0194 \\
\hline $\mathrm{V} 21$ & 0.95 & 1.05 & 1.0435 & 1.0243 \\
\hline $\mathrm{V} 22$ & 0.95 & 1.05 & 1.0448 & 1.0396 \\
\hline V23 & 0.95 & 1.05 & 1.0472 & 1.0372 \\
\hline $\mathrm{V} 24$ & 0.95 & 1.05 & 1.0484 & 1.0372 \\
\hline V25 & 0.95 & 1.05 & 1.0142 & 1.0192 \\
\hline V26 & 0.95 & 1.05 & 1.0494 & 1.0422 \\
\hline V27 & 0.95 & 1.05 & 1.0472 & 1.0452 \\
\hline V28 & 0.95 & 1.05 & 1.0243 & 1.0283 \\
\hline V29 & 0.95 & 1.05 & 1.0439 & 1.0419 \\
\hline V30 & 0.95 & 1.05 & 1.0418 & 1.0397 \\
\hline
\end{tabular}

Table 5. Comparison of real power loss

\begin{tabular}{ll}
\hline Method & Minimum loss (MW) \\
\hline Evolutionary programming [21] & 5.0159 \\
Genetic algorithm [22] & 4.665 \\
Real coded GA with Lindex as SVSM [23] & 4.568 \\
Real coded genetic algorithm [24] & 4.5015 \\
Proposed PSOA method & 4.2502 \\
\hline
\end{tabular}

\section{CONCLUSION}

In this paper, Passerine bird Swarm Optimization (PSOA) algorithm has been successfully implemented to solve optimal reactive power dispatch problem. By using the Passerine bird communications and behaviour, five basic rules have been created in the PSOA approach to solve the optimal reactive power dispatch problem. Key aspect is to reduce the real power loss and also to keep the variables within the limits. Proposed Passerine Swarm Optimization Algorithm (PSOA) has been tested in standard IEEE 30 bus test system and simulations results reveal about the better performance of the proposed algorithm in reducing the real power loss and enhancing the static voltage stability margin.

\section{REFERENCES}

[1] O.Alsac,and B. Scott, "Optimal load flow with steady state security,"IEEE Transaction. PAS, pp. 745-751, 1973.

[2] Lee K. Y., Paru Y. M., Oritz J. L., "A united approach to optimal real and reactive power dispatch," IEEE Transactions on power Apparatus and systems, PAS-104, pp. 1147-1153, 1985.

[3] A. Monticelli , M .V. F Pereira , S. Granville., "Security constrained optimal power flow with post contingency corrective rescheduling," IEEE Transactions on Power Systems, PWRS-2, no. 1, pp. 175-182, 1987.

[4] Deeb N , Shahidehpur S. M., "Linear reactive power optimization in a large power network using the decomposition approach," IEEE Transactions on power system, vol. 5, no. 2, pp. 428-435, 1990.

[5] E. Hobson., "Network consrained reactive power control using linear programming," IEEE Transactions on power systems, PAS-99, no. 4, pp. 868-877, 1980.

[6] K. Y Lee ,Y. M Park, and J. L Oritz, "Fuel-cost optimization for both real and reactive power dispatches," IEE Proc, vol. 131C, no. 3, pp. 85-93, 1984. 
[7] M.K. Mangoli, and K.Y. Lee, "Optimal real and reactive power control using linear programming," Electr.Power Syst.Res, vol. 26, pp. 1-10, 1993.

[8] Aparajita Mukherjee, Vivekananda Mukherjee, "Solution of optimal reactive power dispatch by chaotic krill herd algorithm," IET Gener. Transm. Distrib, vol. 9, no. 15, pp. 2351-2362, 2015.

[9] Hu, Z., Wang, X. \& Taylor, G, "Stochastic optimal reactive power dispatch: Formulation and solution method," Electr. Power Energy Syst, vol. 32, pp. 615-621. 2010.

[10] Mahaletchumi A/P Morgan, Nor Rul Hasma Abdullah, Mohd Herwan Sulaiman, Mahfuzah Mustafa and Rosdiyana Samad, "Computational intelligence technique for static VAR compensator (SVC) installation considering multicontingencies (N-m)," ARPN Journal of Engineering and Applied Sciences, vol. 10, no. 22, Dec 2015.

[11] Mohd Herwan Sulaiman, Zuriani Mustaffa, Hamdan Daniyal, Mohd Rusllim Mohamed and Omar Aliman, "Solving Optimal Reactive Power Planning Problem Utilizing Nature Inspired Computing Techniques," ARPN Journal of Engineering and Applied Sciences, vol. 10, no. 21, pp. 9779-9785, Nov 2015.

[12] Mohd Herwan Sulaiman, Wong Lo Ing, Zuriani Mustaffa and Mohd Rusllim Mohamed, "Grey Wolf Optimizer for Solving Economic Dispatch Problem with Valve-Loading Effects," ARPN Journal of Engineering and Applied Sciences, vol. 10, no. 21, pp. 9796-9801, Nov 2015.

[13] Pandiarajan, K. \& Babulal, C. K., "Fuzzy harmony search algorithm based optimal power flow for power system security enhancement," International Journal Electric Power Energy Syst, vol. 78, pp. 72-79. 2016.

[14] Mustaffa, Z., Sulaiman, M. H., Yusof, Y., Kamarulzaman, S. F., "A novel hybrid metaheuristic algorithm for short term load forecasting," International Journal of Simulation: Systems, Science and Technology, vol. 17, no. 41, pp. 6.1-6.6. 2017.

[15] Anderson, T. R., "Biology of the ubiquitous house sparrow: From genes to populations," Oxford: Oxford University Press, 2006.

[16] Barnard, C. J., \&Sibly, R. M., "Producers and scroungers: A general model and its application to captive flocks of house sparrows," Animal Behavior, vol. 29, pp. 543-550, 2018.

[17] Beauchamp, G. "The effect of group size on mean food intake rate in birds," Biological Reviews, vol. 73, pp. 449-472, 1998.

[18] Beauchamp, G., "Group-size effects on vigilance: A search for mechanisms," Behavioral Processes, vol. 63, pp. 111-121, 2003.

[19] Bednekoff, B. A., \& Lima, S. L., "Randomness, chaos and confusion in the study of antipredator vigilance," Trends in Ecology and Evolution, vol. 13, pp. 284-287, 1998.

[20] Coolen, I., Giraldeau, L. A., \& Lavoie, M., "Head position as an indicator of producer and scrounger tactics in a ground-feeding bird," Animal Behavior, vol. 61, pp. 895-903, 2001. doi:10.1006/anbe.2000.1678.

[21] $\mathrm{Wu} \mathrm{Q} \mathrm{H}$, Ma J T. "Power system optimal reactive power dispatch using evolutionary programming”, IEEE Transactions on power systems, vol. 10, no. 3, pp. 1243-1248, 1995.

[22] S. Durairaj, D. Devaraj, P.S. Kannan, "Genetic algorithm applications to optimal reactive power dispatch with voltage stability enhancement," IE(I) Journal-EL, vol. 87, Sept 2006.

[23] D.Devaraj, "Improved genetic algorithm for multi-objective reactive power dispatch problem," European Transactions on electrical power, vol. 17, pp. 569-581, 2007.

[24] P. Aruna Jeyanthy and Dr. D. Devaraj., "Optimal Reactive Power Dispatch for Voltage Stability Enhancement Using Real Coded Genetic Algorithm," International Journal of Computer and Electrical Engineering, vol. 2, no. 4, pp. 1793-8163, Aug 2010. 